\title{
Hepatoduodenal fistula: A rare complication of liver abscess
}

\author{
Ravikant Kumar, Pavan Kumar, K. N. Saxena, Manisha Dwivedi \\ Department of Gastroenterology, MLN Medical College, Allahabad, Uttar Pradesh, India
}

\begin{abstract}
\end{abstract}
\section{Introduction}

Amebiasis, caused by protozoa Entamoeba histolytica, is found worldwide. ${ }^{[1]}$ Amebic liver abscess (ALA) is the most common form of extraintestinal amebiasis. ${ }^{[2]}$ ALA may be complicated by rupturing into the thorax, pericardium, and peritoneum. Rupture into the duodenum is rare, and only a few cases are described in literature. ${ }^{[3]}$ We report a case of ALA rupturing into the duodenum.

\section{Case Report}

A 56-year-old chronic alcoholic male presented with a history of pain in the right upper abdomen which was mild to moderate in intensity, dull aching in character with occasional throbbing sensation with no radiation to any other site, low-grade fever for 7 days, and three episodes of vomiting of reddish-brown material on the day of admission. After vomiting, he got relief of pain to some extent. There was no history of jaundice, melena, or nonsteroidal anti-inflammatory drugs use. On examination, he was febrile and pallor was present. There was

\begin{tabular}{|l|c|}
\hline \multicolumn{3}{|c|}{ Access this article online } \\
Website: & Quick Response Code \\
www.jdeonline.in & \\
\hline &
\end{tabular}

tenderness in the right upper quadrant, and liver was palpable $4 \mathrm{~cm}$ below the subcostal margin. The spleen was not palpable and free fluid was absent.

The patients' hemoglobin was $9.2 \mathrm{~g} / \mathrm{dl}$ and total leukocyte count was $12,600 / \mathrm{cc}$ with $74 \%$ mononuclear cells. Serum bilirubin was $1.40 \mathrm{mg} / \mathrm{dl}$, aspartate transaminase/alanine transaminase was 55/64 IU/L, and alkaline phosphatase was 624 IU/L. Ultrasonography (USG) showed hepatomegaly with heterogeneous cystic lesions containing air pocket in the left lobe (segments 2 and 4 ) of the liver. In view of brownish vomiting, gastroduodenoscopy was performed which showed ulcer with fistulous opening in the first part of the duodenum [Figure 1]. Computed tomography scan of the abdomen showed cystic lesion with air pocket in segments 2 and 4 of the liver with communication to the duodenum [Figures 2 and 3]. ELISA for E. histolytica came positive.

He refused for surgical intervention and managed with metronidazole and symptomatic treatment. He improved on conservative treatment, and follow-up USG showed a decrease in the size of abscess cavity. Follow-up gastroduodenoscopy at 4 weeks showed healing of ulcer with closure of duodenal opening of fistula.

This is an open access article distributed under the terms of the Creative Commons Attribution-NonCommercial-ShareAlike 3.0 License, which allows others to remix, tweak, and build upon the work non-commercially, as long as the author is credited and the new creations are licensed under the identical terms.

For reprints contact: reprints@medknow.com

How to cite this article: Kumar R, Kumar P, Saxena KN, Dwivedi M. Hepatoduodenal fistula: A rare complication of liver abscess. J Dig Endosc 2016;7:150-2. 


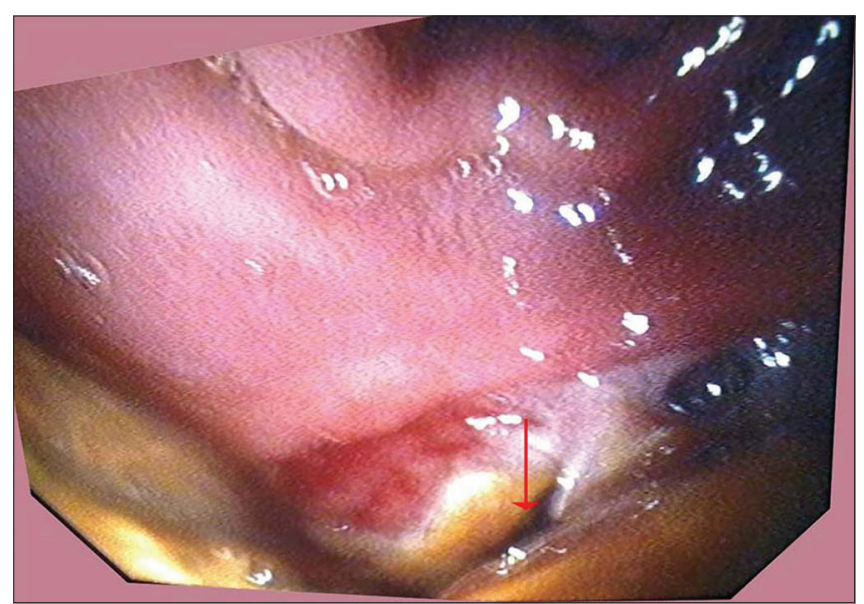

Figure 1: Endoscopy image showing ulcer with opening of fistula in the first part of duodenum

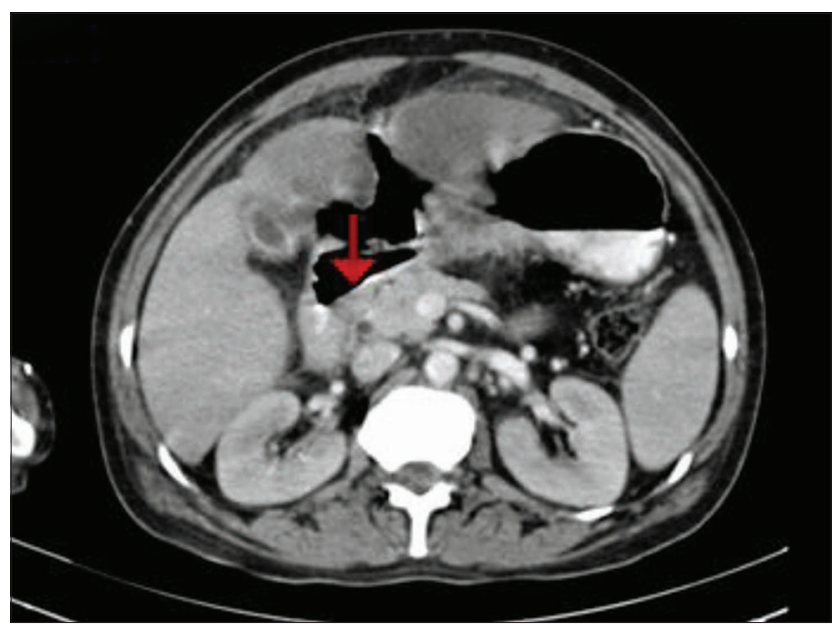

Figure 2: Computed tomography scan of the abdomen showing abscess in the left lobe of the liver with air pockets in abscess cavity communicating with the first part of duodenum (arrow mark)

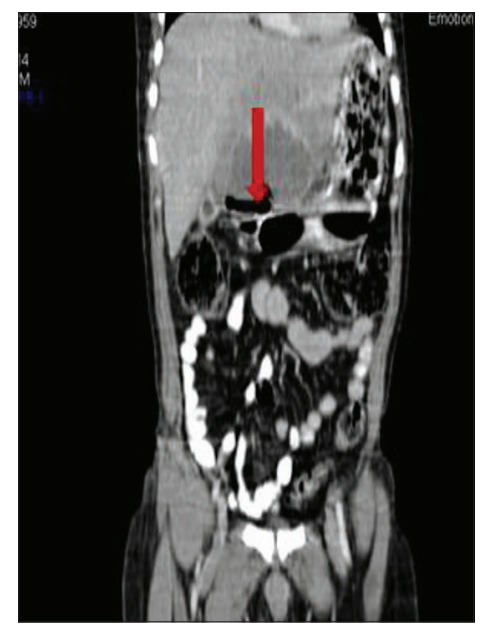

Figure 3: Computed tomography scan of the abdomen showing liver abscess with air pockets (arrow mark)

\section{Discussion}

ALA is endemic in India, and its incidence varies between 3\% and $9 \%$ of all cases of amebiasis. ${ }^{[4]}$ ALA rupture into the pleural and peritoneal cavities is a relatively common phenomenon. ${ }^{[5]}$ Rupture of ALA into gastrointestinal tract is uncommon, and only a handful of cases are reported in literature. Mowji et al. described the first case of ALA with hepatoduodenal fistula with radiological confirmation in 1987. ${ }^{[3]}$

The presentations of hepatoduodenal fistula secondary to ALA can be as an anchovy sauce color vomitus or stool, hematemesis, or malena. ${ }^{[6]}$ In our case, vomiting of brown material raises the suspicion of fistula which was confirmed by endoscopy and imaging. Identification of the intraluminal orifice of the fistula by endoscopy is difficult without the help of other imaging modalities. ${ }^{[7]}$

Surgery is the definitive therapy, but response to conservative treatment has been described..$^{[8]}$ Conservative treatment includes metronidazole for clearance in the extraintestinal site and diloxanide furoate or paromomycin for luminal clearance. Spontaneous closure of fistula can be seen within 5 weeks of conservative management. ${ }^{[9]}$ If no improvement is observed on conservative management or if there is clinical worsening, surgical excision of the fistulous tract is an option. Complications of hepatoduodenal fistulas include sepsis, debilitation, and electrolyte imbalance.

\section{Conclusion}

Hepatoduodenal fistula is a very rare complication of ALA, and a high index of suspicion is required for early diagnosis, especially if patients present with an anchovy sauce color vomitus or stool. Management can be conservative or surgical. We have managed this patient conservatively.

\section{Financial support and sponsorship}

Nil.

\section{Conflicts of interest}

There are no conflicts of interest.

\section{References}

1. Grecu F, Bulgariu T, Blanaru O, Dragomir C, Lunca C, Stratan I, et al. Invasive amebiasis. Chirurgia (Bucur) 2006;101:539-42.

2. Rao S, Solaymani-Mohammadi S, Petri WA Jr., Parker SK. Hepatic amebiasis: A reminder of the complications. Curr Opin Pediatr 2009;21:145-9.

3. Mowji PJ, Cohen AJ, Potkin B, Viltuznik J. Amebic liver abscess with hepatoduodenal fistula. Am J Gastroenterol 1987;82:558-9.

4. Peters RS, Gitlin N, Libke RD. Amebic liver abscess. Annu Rev Med 1981;32:161-74. 
5. Budhiraja S, Dhatt GS, Babra RS. Hepatogastric fistula in a pediatric patient. Pediatr Surg Int 2006;22:853-5.

6. Siddiqui MN, Rizvi SB, Ahmed M, Rizvi IH. Case report: Amoebic liver abscess complicated by a hepatoduodenal fistula. Clin Radiol 1992;46:142-3.

7. Lee JK, Stein SL. Radiographic and endoscopic diagnosis and treatment of enterocutaneous fistulas. Clin Colon Rectal Surg 2010;23:149-60.

8. Moazam F, Nazir Z. Amebic liver abscess: Spare the knife but save the child. J Pediatr Surg 1998;33:119-22.

9. Sheldon GF, Gardiner BN, Way LW, Dunphy JE. Management of gastrointestinal fistulas. Surg Gynecol Obstet 1971;133:385-9. 